\title{
Subcellular effects of myocyte-specific androgen receptor overexpression in mice
}

\author{
Mutaz Musa ${ }^{1}$, Shannon M Fernando ${ }^{1}$, Diptendu Chatterjee ${ }^{2}$ and D Ashley Monks ${ }^{1,2}$ \\ ${ }^{1}$ Institute of Medical Science, University of Toronto, Toronto, Ontario, Canada M5S 3G3 \\ ${ }^{2}$ Department of Psychology, University of Toronto at Mississauga, 3359 Mississauga Road, Mississauga, Ontario, Canada L5L 1C6 \\ (Correspondence should be addressed to D A Monks at Department of Psychology, University of Toronto at Mississauga; Email: ashley.monks@utoronto.ca)
}

\begin{abstract}
Although androgen receptor (AR) within myocytes is thought to mediate many of the effects of testosterone and other androgens on skeletal muscle, little is known about the functions of AR within these cells. We, therefore, studied the ultrastructure of skeletal muscle of HSA-AR transgenic (Tg) mice that overexpress AR selectively in myocytes and exhibit neuromuscular atrophy. We examined male HSA-AR mice from two different founding lines: L78 (lower copy number and less severe phenotype) and L141 (higher copy number and more severe phenotype) and compared these to wild-type (Wt) brothers. We also examined testosterone-treated female mice from these two lines and compared them both to their $\mathrm{Wt}$ sisters and to vehicle-treated controls. Ultrastructural examination of extensor digitorum longus sections using transmission electron microscopy revealed remarkably disorganized myofibrils in male $\mathrm{Tg}$ and testosterone-treated female $\mathrm{Tg}$ mice. Quantification of ultrastructural pathology indicated reduced
\end{abstract}

myofibril width, hypertrophic and hyperplastic intermyofibrillar mitochondria, and pronounced glycogen accumulation in HSA-AR males of both lines. Reduced myofibrillar width and increases in mitochondrial number, size, and volume density were also observed in testosterone-treated HSA-AR females, although glycogen accumulation was not observed. Structural abnormalities in mitochondria were also associated with increases in electron transport chain activity and systemic resting metabolic rate, indicative of hypermetabolism. We find that overexpression of AR in myocytes of HSA-AR mice results in alterations in myofibrils, mitochondria, and glycogen. Alterations in myofibrils and mitochondria appear to result from acute actions of testosterone, whereas those on glycogen do not. Pathology of myofibrils and/or mitochondria may, therefore, mediate in part the neuromuscular atrophy observed in HSA-AR mice.

Journal of Endocrinology (2011) 210, 93-104

\section{Introduction}

Androgens, including testosterone and synthetic derivatives known as anabolic-androgenic steroids, are therapeutically used for some types of muscle wasting (Orr \& Fiatarone Singh 2004) and are widely abused in sport as anabolic agents. Abundant evidence indicates that androgens, such as testosterone, promote skeletal muscle mass in men (Forbes et al. 1992, Marin et al. 1992, Ferrando et al. 2002, 2003, Schroeder et al. 2003). For example, reductions in androgens in men are associated with loss of muscle mass and/or strength (Forbes et al. 1992, Mauras et al. 1998, Basaria et al. 2002, Wang et al. 2004), and pharmacological supplementation with androgen increases muscle mass in a dose-dependent manner (Bhasin et al. 1996, 2005, Storer et al. 2003, 2008, Woodhouse et al. 2003). However, the physiological, cellular, and molecular mechanisms that mediate androgenic action on skeletal muscle remain incompletely understood (Herbst \& Bhasin 2004). The application of androgens for therapeutic purposes is limited by side effects in tissues other than muscle, which generally contraindicate their use in women and put men at risk for androgen-mediated pathology such as prostate disease. Furthermore, recent clinical trials of androgen supplementation in older men to improve body composition and muscle strength were halted due to adverse cardiovascular effects of this treatment (Basaria et al. 2010), highlighting the potentially dangerous side effects of systemic androgen therapy. As such, there is considerable interest in more targeted therapeutic options for treating muscle atrophy.

Although androgenic effects on muscle are generally presumed to occur via actions on myocyte androgen receptor (AR), only recently has this idea been tested with myocytespecific genetic manipulation of AR (MacLean \& Handelsman 2009, Ophoff et al. 2009, Chambon et al. 2010, Fernando et al. 2010, Huguenard et al. 2011). Selective genetic ablation of AR within myocytes reduces lean body mass percentage (Ophoff et al. 2009) and limb muscle strength and myofibrillar organization (Chambon et al. 2010), although alterations in muscle size were not consistently observed in these studies. Similarly, selective overexpression of AR within myocytes of HSA-AR mice and rats using HSA-AR transgenes increases lean body mass percentage of these animals (Niel et al. 2009, 
Fernando et al. 2010). Intriguingly, the increase in lean body mass percentage in HSA-AR mice is associated with drastic reductions in overall body mass and with muscle wasting and weakness (Monks et al. 2007). Copy number and transgene expression level within muscle likely account for the different phenotypes of HSA-AR rats and mice, as well as differences between founding lines of HSA-AR mice. This is because founding lines of HSA-AR mice with a lower copy number (L78) have a less severe phenotype than founding lines (L141) with a higher copy number (Monks et al. 2007).

HSA-AR mice allow us to probe the biological functions of myocyte AR. AR is a transcription factor, and so it is perhaps unsurprising that alterations in gene expression are observed in the skeletal muscle of these mice (Monks et al. 2007, Mo et al. 2010). HSA-AR mice also have alterations in muscle fiber number and/or size and exhibit several histopathological signs, including split fibers, internalized nuclei, and angulated fibers (Monks et al. 2007). In particular, HSA-AR mice have marked increases in diaphorase staining of muscle fibers, suggestive of hypermetabolism (Monks et al. 2007). Indeed, HSA-AR rats exhibit increased resting metabolic rate (RMR) as well as increased electron transport chain (ETC) activity within skeletal muscle, providing a potential mechanism whereby myocyte AR might reduce adipose tissue (Fernando et al. 2010).

In order to gain further insights into the subcellular effects of increased AR signaling in myocytes, we performed an ultrastructural study of HSA-AR mouse skeletal muscle. We first examined male mice and subsequently assessed the ability of acute testosterone treatment to reproduce these effects in females. The results of these studies prompted us to further characterize glycogen and mitochondria in skeletal muscle of HSA-AR mice.

\section{Materials and Methods}

\section{Ethics statement}

All animal experiments conformed to NIH guidelines and were approved by the University Animal Care Committee of the University of Toronto Mississauga (Approved protocol \# 20007262).

\section{Animals}

HSA-AR The production, genotyping, and phenotyping of HSA-AR transgenic ( $\mathrm{Tg}$ ) mice has been described elsewhere (Monks et al. 2007). The two founding lines (L78 and L141) of HSA-AR mice, which differ in the copy number of the transgene and have corresponding differences in the severity of the neuromuscular atrophy (L178<L141), have previously been characterized. Behavioral, body composition, histological, and candidate gene expression data have previously been reported for a subset of these animals (Monks et al. 2007, Fernando et al. 2010).

\section{Overview}

In this study, extensor digitorum longus (EDL) and anterior tibialis (AT) muscles were dissected from hind limbs of subjects. The EDL was used for transmission electron microscopy and the AT was used for light microscopy and biochemical assay. Initially, unmanipulated wild-type (Wt) and Tg L78 and L141 males were examined. Then, the role of androgens was assessed using testosterone- or vehicle (VEH)treated Wt and Tg L78 females. To investigate the role of the level of AR overexpression, this test was repeated with females from the L141 line. All animals were housed in controlled laboratory conditions with access to food and water ad libitum. All morphometric analyses were carried out using Image J software from NIH (Bethesda, Maryland, USA).

\section{Subjects}

In all experiments, sibling Wt controls were used for $\mathrm{Tg}$ subjects. First, ten unmanipulated L78 males (five Wt and five $\mathrm{Tg}$ ) were used (age 144-148 days, mean of 146 days). For the second portion of the study, 32 L78 females were equally divided into four treatment conditions: i) Wt VEH-treated (8), ii) Wt testosterone-treated (8), iii) Tg VEH-treated (8), and iv) Tg testosterone-treated (8) animals (age 97-202 days, mean of 133 days). In addition, 16 L141 females were equally divided into four treatment conditions: i) Wt VEH-treated (4), ii) Wt testosterone-treated (4), iii) Tg VEH-treated (4), and iv) Tg testosterone-treated (4) animals (age 100-264 days, mean of 143 days). Finally, six L141 males (three Wt and three $\mathrm{Tg}$ ) were used. To promote viability, one $\mathrm{Tg}$ and its $\mathrm{Wt}$ brother were castrated at 2 months of age (age at dissection: 96-116 days, mean of 105 days). The sample size of this group was small due to the poor viability of L141 males. Furthermore, tissue from these males was exclusively used for electron microscopy, and we were unable to perform histological or biochemical analysis on them. An additional two L141 female mice were later added to the Wt-VEH and Tg-T groups for the ETC assays (aged 103 and 219 days), resulting in a total of 18 animals in those tests. In addition, five Wt and six Tg L78 males aged 24 weeks were later used for RMR and ETC assay experiments.

\section{Surgery and dissection}

Testosterone and VEH implants (6 $\mathrm{mm}$ release length) were prepared and implanted as described previously (Monks et al. 2007). After 1 week, the animals were killed with $0 \cdot 1 \mathrm{ml}$ sodium pentobarbital and EDL and AT muscles were rapidly dissected. Dissected EDL for electron microscopy was fixed in $1 \%$ glutaraldehyde in $0.1 \mathrm{M}$ phosphate buffer for $15 \mathrm{~min}$ and then cut at the middle with a scalpel into three or four discs, each $\sim 1 \mathrm{~mm}$ thick. These discs were stored in glutaraldehyde fix for subsequent electron microscopy. Dissected EDL for ETC assays was frozen in liquid nitrogen and stored at $-80{ }^{\circ} \mathrm{C}$ until use. 
Dissected AT was oriented in cryomolds containing Tissuetek, flash frozen in liquid nitrogen, and subsequently stored at $-80^{\circ} \mathrm{C}$ until used for histochemical analysis.

\section{Transmission electron microscopy}

Sections were removed from glutaraldehyde and fixed in 1\% sodium osmium tetroxide in $0 \cdot 1 \mathrm{M}$ phosphate buffer. They were then dehydrated in graded alcohol, infiltrated in graded epoxy resin and propylene oxide, embedded in 100\% epoxy resin, cut into ultra thin transections $(90 \mathrm{~nm})$, and stained with lead citrate and uranyl acetate. Sections were then viewed on a Hitachi-7000 transmission electron microscope at $75 \mathrm{kV}$ acceleration. Myofibers were sampled by photographing myofibers in alternate EM grids. For each subject, ten micrographs were sampled to obtain measurements of sarcomere width and mitochondrial number, size, and volume density from ten distinct myocytes. Measurements of sarcomere width were performed on ten sarcomeres per photomicrograph. Images for sarcomere and mitochondrial analysis were taken at $20000 \times$ and $40000 \times$ magnification respectively. Glycogen was analyzed using the latter magnification. Core, intermyofibrillar mitochondria rather than subsarcolemmal mitochondria were photographed. Furthermore, myofibers narrower than $15 \mu \mathrm{m}$ in diameter were excluded from analysis to avoid inclusion of subsarcolemmal mitochondria.

Measurements Sarcomere width (short axis) and height (long axis) were measured as well as mitochondria number, profile area, and volume density. Mitochondria number was measured as the number of whole mitochondria appearing in an electron micrograph of an area of $8.92 \mu \mathrm{m}^{2}$ in a myofiber. Mitochondria profile areas were measured by tracing mitochondria on electron micrographs taken at $40000 \times$ using ImageJ. Mitochondrial volume densities were calculated using the test-point method (Weibel 1979) on a $12 \times 12(144$ point) test grid. The grid was generated using the Grid plug-in for ImageJ. Differences in glycogen content were estimated by calculating the proportion of micrographs that displayed glycogen granules.

\section{Light microscopy}

AT muscle was sectioned at $10 \mu \mathrm{m}$ thick with a cryostat at $-22{ }^{\circ} \mathrm{C}$. Histochemically stained serial sections were used to examine glycogen (PAS), mitochondria (GTC), succinate dehydrogenase $(\mathrm{SDH})$, and fast myosin. Fast myosin immunostaining and SDH staining were performed as described previously (Fernando et al. 2010) to determine the proportion of type I (slow; negative for fast myosin), type IIa (fast oxidative; positive for fast myosin and positive for $\mathrm{SDH}$ ), and type IIb (fast glycolytic; positive for fast myosin and negative or weak for SDH) fibers. PAS stain and analysis was performed as described (van der Laarse et al. 1992, Fairchild \& Fournier 2004). Briefly, sections were fixed in
Carnoy's Fix, oxidized with periodic acid for $10 \mathrm{~min}$, and finally stained in Schiff's reagent. High-glycogen content was marked by darker pink-red staining. Amylase-treated sections (i.e. sections in which glycogen has been digested) from each subject were also stained and used as a negative control. Photomicrographs were taken on an Olympus BX-51 compound light microscope with a mounted Olympus D70 CCD camera attached to a computer. The microscope was allowed to stabilize for $15 \mathrm{~min}$ with the bulb set at $11 \mathrm{~V}$ prior to photography. In total, three regions of one PAS and one amylase-treated section from the same subject were photographed at $40 \times$ magnification. All images were converted to 8 -bit grayscale and mean gray values were measured (in pixels). To convert from pixels to optical density units (OD), a calibrated Kodak No. 3 Step-tablet was used along with Rodbard calibration function on ImageJ software. All measures were corrected by subtracting amylase-treated OD values. Changes in mitochondrial content were assayed with one-step GTC stain. Slides were stained in GTC for $30 \mathrm{~s}$, differentiated in glacial acetic acid, dehydrated, and coverslipped with permount.

\section{Indirect calorimetry measures}

$\mathrm{O}_{2}$ consumption was measured through the use of an opencircuit indirect calorimetry system (Qubit Systems, Kingston, ON, Canada) as described previously (Fernando et al. 2010), with necessary modifications for animal size. Animals were placed inside a gas-exchange chamber and room air was pumped through the chamber at a flow rate of $100 \mathrm{ml} / \mathrm{min}$. Outflow oxygen concentration was measured by a flow-through oxygen analyzer and displayed by gas-exchange software (Logger Pro V.3, Vernier Software, Beaverton, OR, USA). Measures were recorded every $250 \mathrm{~ms}$. Animals were kept in the chamber until outflow oxygen concentration levels were stable, which was defined by no deviation in concentration of more than $0.02 \%$ over a period of $30 \mathrm{~min}$. The difference between final outflow oxygen concentration and inflow concentration (i.e. concentration of oxygen in room air) was used to determine oxygen uptake (in $\mu \mathrm{l} / \mathrm{min}$ ). Dividing oxygen uptake by total body mass of the mouse provided an estimate of RMR (in J/g per min).

\section{ETC assays}

EDL muscles were stored at $-80{ }^{\circ} \mathrm{C}$ for mitochondrial enzyme activity assays. Biochemical assays of mitochondrial enzyme activity in these muscles were performed using the method of Kirby et al. (2007), as described previously (Fernando et al. 2010).

\section{Statistical analysis}

$\mathrm{Wt}$ and $\mathrm{Tg}$ males were compared using two-way independent samples $t$-tests. Measures in the females were analyzed using two-way multivariate ANOVA with genotype and treatment 
as factors. Fiber typing analysis was performed using a mixed model ANOVA with genotype and treatment as betweensubject factors and fiber type as a within-subject factor. In both cases, subsequent pairwise comparisons were made using Tukey tests. As proportion values are discontinuous, glycogen percentage and volume density values were transformed using an arcsine function prior to statistical analysis.

\section{Results}

\section{Ultrastructure of L78 and L141 males}

Transmission electron micrographs were used to qualitatively survey myofiber ultrastructure (Fig. 1). Wt myofibers were organized into fibrils comprising highly structured sarcomeres. Mitochondria appear in pairs in the intermyofibrillar region typically on either side of the Z-line within the span of the I-band. L78 Tg males showed visible alterations in myofiber ultrastructure. Mitochondria appeared larger, hyperplastic, and dysmorphic. Fibrils were markedly
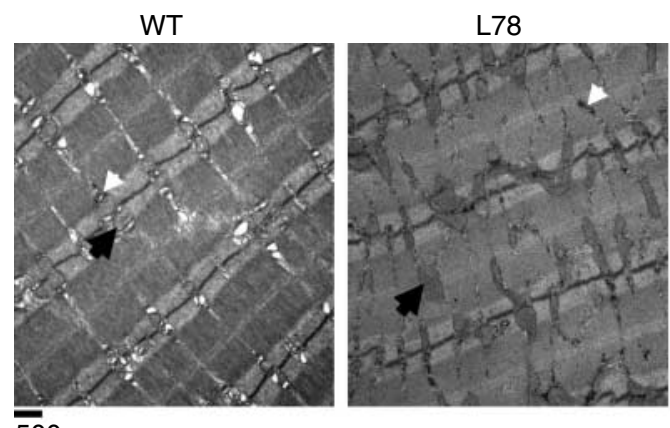

$\overline{500} \mathrm{~nm}$
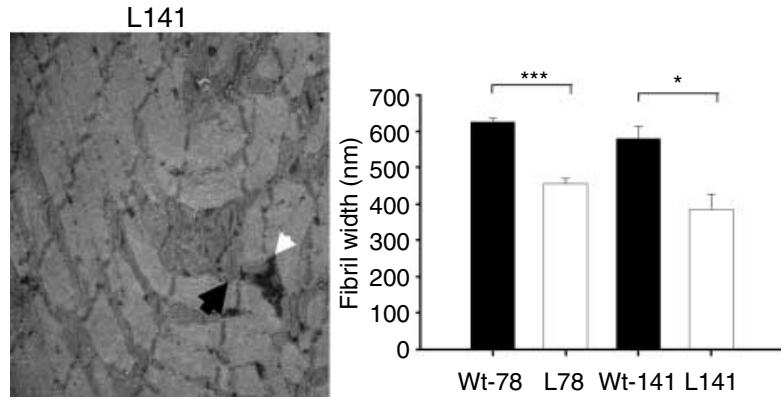

Figure 1 Ultrastructure of male HSA-AR transgenic mouse skeletal muscle. Electron micrographs of extensor digitorum longus (EDL) muscle samples from Wt mice or from L78 transgenic (L78 Tg) or L141 transgenic (L141 Tg) brothers. Wt myofibers contain orderly sarcomeres with pairs of mitochondria located between fibrils in the I-band. Examples of interfibrillar mitochondria are indicated with black arrows. Transgenic males exhibited larger and more numerous interfibrillar mitochondria and additionally show increased interfibrillar granular glycogen (examples of which are indicated with white arrowheads). $20000 \times$ magnification, scale bar $=500 \mathrm{~nm}$. (Right) Graph depicting average fibril width for each genotype (three to five subjects per group, age ranged from 96 to 148 days). Bar graphs represent mean + S.E.M. ${ }^{*} P<0 \cdot 05$; $* * * P<0 \cdot 001$ disorganized and sarcomere packing appeared disrupted. L141 myofibers showed many of the same features as L78 but with greater severity. Large clusters of mitochondria and glycogen granules were visible and fibril disorganization was very prominent.

As HSA-AR mice show motor deficits and reduced muscle strength, changes in sarcomere dimensions were examined in both lines. No differences were found in sarcomere length (long axis; data not shown), but both Tg L78 $\left(t_{2,8}=9 \cdot 46\right.$; $P<0 \cdot 001)$ and Tg L141 $\left(t_{2,4}=3.59 ; P<0 \cdot 05\right)$ showed narrower myofibrils than Wt littermates (Fig. 1).

Large clusters of intermyofibrillar glycogen granules were evident in $\mathrm{Tg}$ males. These changes were quantified by calculating the proportion of electron micrographs showing granular glycogen. As expected, the percentage of micrographs presenting with glycogen granules was greater in both Tg L78 males $\left(t_{2,8}=3.99 ; P=0.004\right)$ and Tg L141 males $\left(t_{2,4}=4 \cdot 07 ; P=0 \cdot 015\right)$ relative to $\mathrm{Wt}$ brothers (Fig. $\left.2 \mathrm{~A}\right)$. The increase in glycogen content in L78 males was confirmed by PAS staining, the calculated relative $\mathrm{OD}$ of which was greater in Tg males relative to $\mathrm{Wt}$ littermates $\left(t_{2,8}=3.30 ; P<0 \cdot 05\right.$; Fig. 2B and C).

\section{Increased mitochondrial content and activity in HSA-AR males}

We assessed intermyofibrillar mitochondrial content using transmission electron microscopy and measured intermyofibrillar mitochondrial number, profile area, and calculated volume density (i.e. the proportion of cell volume occupied by mitochondria). The volume density of mitochondria was greater in L78 $\mathrm{Tg}$ relative to Wt $\left(t_{2,8}=3.53 ; P=0.008\right.$; Fig. 3A). In addition, $\mathrm{Tg}$ males had a numerically greater mitochondrial mean profile area, but this difference did not reach significance $\left(t_{2,8}=1 \cdot 92 ; P=0 \cdot 09\right.$; Fig. $\left.3 \mathrm{~B}\right)$. On average, Tg L78 males had almost twice the number of mitochondria found in Wt littermates $\left(t_{2,8}=8 \cdot 48 ; P<0 \cdot 001\right.$; Fig. 3C). A similar pattern was observed in L141 males. Mean volume density and mitochondria profile area were approximately three times $\left(t_{2,4}=2 \cdot 85 ; P=0 \cdot 046\right.$; Fig. $\left.3 \mathrm{~A}\right)$ and four times $\left(t_{2,4}=2 \cdot 80 ; \quad P<0 \cdot 05\right.$; Fig. $\left.3 \mathrm{~B}\right)$ greater in $\mathrm{Tg}$ animals respectively. The mean number of mitochondria in L141 Tg male muscle was not significantly different from that in muscle of Wt brothers $\left(t_{2,4}=1 \cdot 07 ; P>0 \cdot 10\right.$; Fig. $\left.3 \mathrm{C}\right)$. The increase in mitochondrial content in L78 males was histochemically confirmed using Gomori trichrome stain (GTC). Muscle fibers with hypertrophic mitochondria exhibit a 'ragged red' appearance when stained with GTC. As predicted, ragged red fibers were found in $\mathrm{Tg} \mathrm{L} 78$ myofibers but not in Wt littermates (Fig. 3D).

We measured activity of enzymes in the ETC in L78 Tg males to determine whether the increase in mitochondrial content was accompanied by an increase in mitochondrial oxidative metabolism. Complexes I, II, and IV showed greater specific activities in $\mathrm{Tg}$ males of both lines relative to $\mathrm{Wt}$ littermates (Table 1), whereas the increase in complex III (cytochrome $b c 1$ complex) activity did not reach statistical 


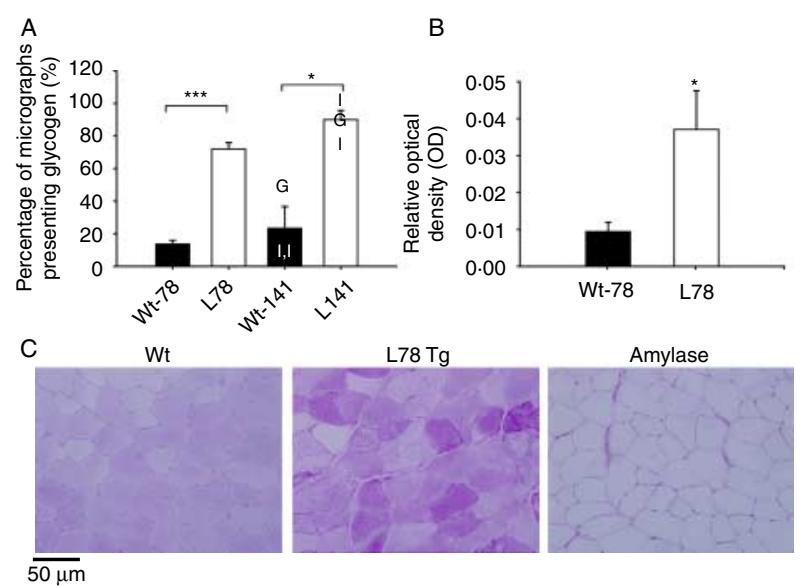

Figure 2 Glycogen is altered in male HSA-AR transgenic mouse skeletal muscle. (A) Graph depicting the percentage of sampled electron micrographs in which glycogen was observed. (B) Graph depicting relative optical density (OD) of periodic acid Schiff stain in EDL sections from L78 transgenic males (L78 Tg) or Wt brothers. Each group had three to five subjects, age ranged from 96 to 148 days. Bar graphs represent mean + S.E.M. ${ }^{*} P<0 \cdot 05$;

$* * * P<0 \cdot 001 . \mathrm{G}=$ value for individual gonadectomized male, $I=$ value for individual intact male. (C) Photomicrographs of periodic acid Schiff stain typical of Wt male, L78 Tg male, and amylase-treated negative control section. Scale bar $=50 \mu \mathrm{m}$. Full colour version of this figure available via http://dx.doi.org/10.1530/ JOE-11-0071.

significance. In particular, specific activities were corrected to citrate synthase to account for total mitochondrial content, indicating that increased activity reflects increased ETC activity within mitochondria, rather than simply a net increase in mitochondrial content (which also appears to be the case). We also used indirect calorimetry to assess RMR in L78 males to determine whether alterations in skeletal muscle mitochondria resulted in systemic increases in oxidative metabolism. As expected, L78 Tg males had greater RMR than their Wt littermates $\left(t_{2,9}=2 \cdot 29 ; P<0 \cdot 05\right.$; Table 1$)$.

Testosterone treatment of $\mathrm{Tg}$ females is sufficient to reproduce many of the ultrastructural alterations observed in $\mathrm{Tg}$ males

To investigate the importance of testosterone in the observed changes, L78 and L141 Tg females were either treated with testosterone or $\mathrm{VEH}$ and electron microscopy was identically performed to that performed for males. Within-subjects ANOVA revealed no significant effect of sampled electron micrograph on any measure in any group. Wt females showed highly organized fibrils and sarcomeres with mitochondria localized within the span of the I-band in the interfibrillar region (Fig. 4). VEH-treated L78 and L141 females likewise showed an orderly myofiber ultrastructure, whereas testosterone-treated L78 and L141 females showed a disruption in fibril organization along with changes in mitochondrial morphology and location (Fig. 4). In contrast to males, an increase in granular glycogen was not obvious in females.
In order to quantify these changes, we measured fibril width and calculated the percentage of micrographs that evidenced glycogen. An interaction between genotype and treatment was observed in both L78 $\left(F_{1,28}=8 \cdot 400, P=0 \cdot 07\right)$ and L171 $\left(F_{1,28}=5 \cdot 174, \quad P=0 \cdot 042\right)$ such that fibril width was significantly reduced in $\mathrm{Tg}$ females that received testosterone relative to all other groups (all comparisons $P<0 \cdot 05$, Fig. 5). In contrast to males, the percentage of micrographs presenting with glycogen was not significantly different among groups in either line (Fig. 5). To confirm this last finding, PAS staining was used to histochemically examine glycogen content. The relative OD of PAS staining did not significantly differ among groups in either line confirming that female myofibers did not show increases in glycogen content in response to $\mathrm{AR}$ overexpression and testosterone treatment (Fig. 5).

\section{Testosterone treatment is sufficient to reproduce effects of $A R$} overexpression on mitochondrial content and activity

To assess whether testosterone treatment is sufficient to elicit the effects of AR overexpression on mitochondrial content and activity, the assessments conducted on males were repeated on Wt and $\mathrm{Tg}$ females treated with either $\mathrm{VEH}$ or testosterone. Mitochondrial number, profile area, and volume density were measured on electron micrographs of EDL myofibers. Multivariate ANOVA revealed a main effect of genotype ( $\mathrm{Tg}$ or $\mathrm{Wt})$ on sarcomere width $\left(F_{1,28}=24 \cdot 095\right.$, $P<0 \cdot 001)$, mitochondria number $\left(F_{1,28}=4 \cdot 211, P=0 \cdot 050\right)$,
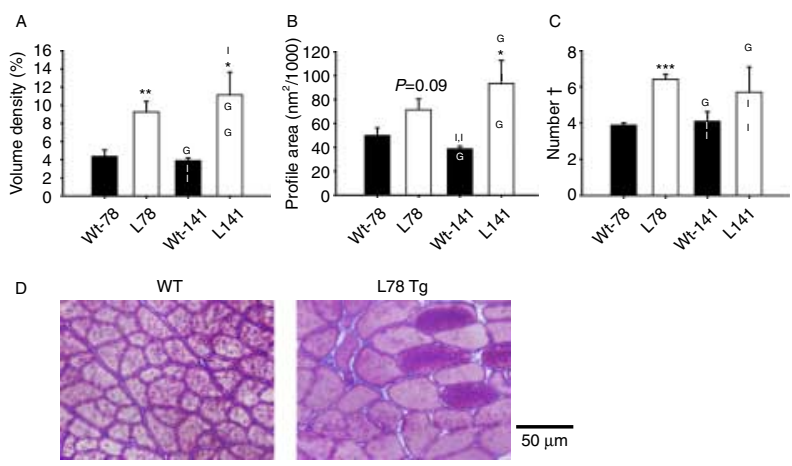

Figure 3 Mitochondria are altered in male HSA-AR transgenic mouse skeletal muscle. (A) Mitochondrial volume density (percentage of myofiber volume occupied by mitochondria) is increased in electron micrographs of EDL muscle of L78 and L141 Tg males. (B) Mitochondrial profile area is greater in L141 Tg males but not significantly so in L78 Tg males. (C) Mitochondrial number is greater in Tg L78 males but not significantly so in L141 Tg males. These measurements were conducted on micrographs of EDL muscle taken at $40000 \times$ magnification (three to five subjects per group, age ranged from 96 to 148 days). ${ }^{*} P<0 \cdot 05 ;{ }^{* *} P<0 \cdot 01$; ${ }_{* * *} P<0 \cdot 001$; $†$ number of mitochondria per $8.92 \mu \mathrm{m}^{2} . \mathrm{G}=$ value for individual gonadectomized male, $I=$ value for individual intact male. (D) AT sections from Wt males stained with Gomori trichrome stain show uniform pale staining whereas sections from Tg L78 males show darkly staining myofibers (ragged red fibers), indicating increased mitochondrial content. Full colour version of this figure available via http://dx.doi.org/10.1530/JOE-11-0071. 
Table 1 Resting metabolic rate (RMR) and respiratory complexes in skeletal muscle of L78 male mice. Transgenic L78 males show increased RMR and activity of complexes I, II, and IV of the respiratory chain. The increase in complex III approached but did not reach statistical significance. Electron transport chain assays were conducted on mitochondria isolated from anterior tibialis muscle

\begin{tabular}{|c|c|c|c|}
\hline Measure & Wt & L78 & Significance \\
\hline Resting metabolic rate (J/g per min) & $0 \cdot 03021 \pm 0 \cdot 0026$ & $0 \cdot 04005 \pm 0 \cdot 0022$ & $F_{1,9}=5 \cdot 225, P=0 \cdot 048$ \\
\hline Complex I specific activity (nmol/min per mg protein) & $166 \cdot 4 \pm 10 \cdot 2$ & $243 \cdot 7 \pm 13 \cdot 9$ & $t_{2,9}=-4 \cdot 317, P=0 \cdot 0019$ \\
\hline Complex II specific activity (nmol/min per mg protein) & $258 \cdot 0 \pm 15 \cdot 2$ & $307 \cdot 3 \pm 5 \cdot 1$ & $t_{2,9}=-3 \cdot 068, P=0 \cdot 0090$ \\
\hline Complex III specific activity (nmol/min per mg protein) & $773 \cdot 0 \pm 20 \cdot 0$ & $854 \cdot 7 \pm 35 \cdot 1$ & $t_{2,9}=-1.907, P=0.0889$ \\
\hline Complex IV specific activity ( $\mathrm{nmol} / \mathrm{min}$ per mg protein) & $646 \cdot 2 \pm 9 \cdot 1$ & $920 \cdot 8 \pm 45 \cdot 1$ & $t_{2,9}=-5 \cdot 973, P=0 \cdot 0004$ \\
\hline
\end{tabular}

$P$ values are reported for independent samples $t$-tests comparing these two groups.

and volume density $\left(F_{1,29}=5.563, P=0.026\right)$ in the L78 line. An additional main effect of treatment (testosterone or $\mathrm{VEH})$ on mitochondrial volume density $\left(F_{1,29}=6 \cdot 483\right.$, $P=0 \cdot 017)$ was observed. An interaction between genotype and treatment was observed for sarcomere width $\left(F_{1,29}=8 \cdot 4\right.$, $P=0 \cdot 07)$, mitochondria number $\left(F_{1,29}=4 \cdot 907, P=0 \cdot 007\right)$, and volume density $\left(F_{1,29}=7.944, P=0.009\right)$. The interaction results from testosterone-treated $\mathrm{Tg}$ animals alone significantly differing from all other groups such that their mitochondria occupied the greatest volume (all comparisons $P<0 \cdot 01$; Fig. 6), had the largest profile area (all comparisons $P<0 \cdot 05$; Fig. 6), and were most numerous (all comparisons $P<0 \cdot 05$; Fig. 6).

A separate multivariate ANOVA was performed for L141 females. This analysis revealed main effects of genotype and treatment on sarcomere width $\left(F_{1,29}=5 \cdot 856\right.$, $\left.P=0.035 ; F_{1,29}=5 \cdot 448, P=0 \cdot 0378\right)$, mitochondrial number $\left(F_{1,29}=10 \cdot 224, \quad P=0 \cdot 008 ; \quad F_{1,29}=13 \cdot 088, \quad P=0 \cdot 0035\right)$, mitochondrial area $\left(F_{1,29}=46 \cdot 791, P<0 \cdot 0001 ; F_{1,29}=\right.$ 58.201, $P<0 \cdot 0001)$, and mitochondrial volume density
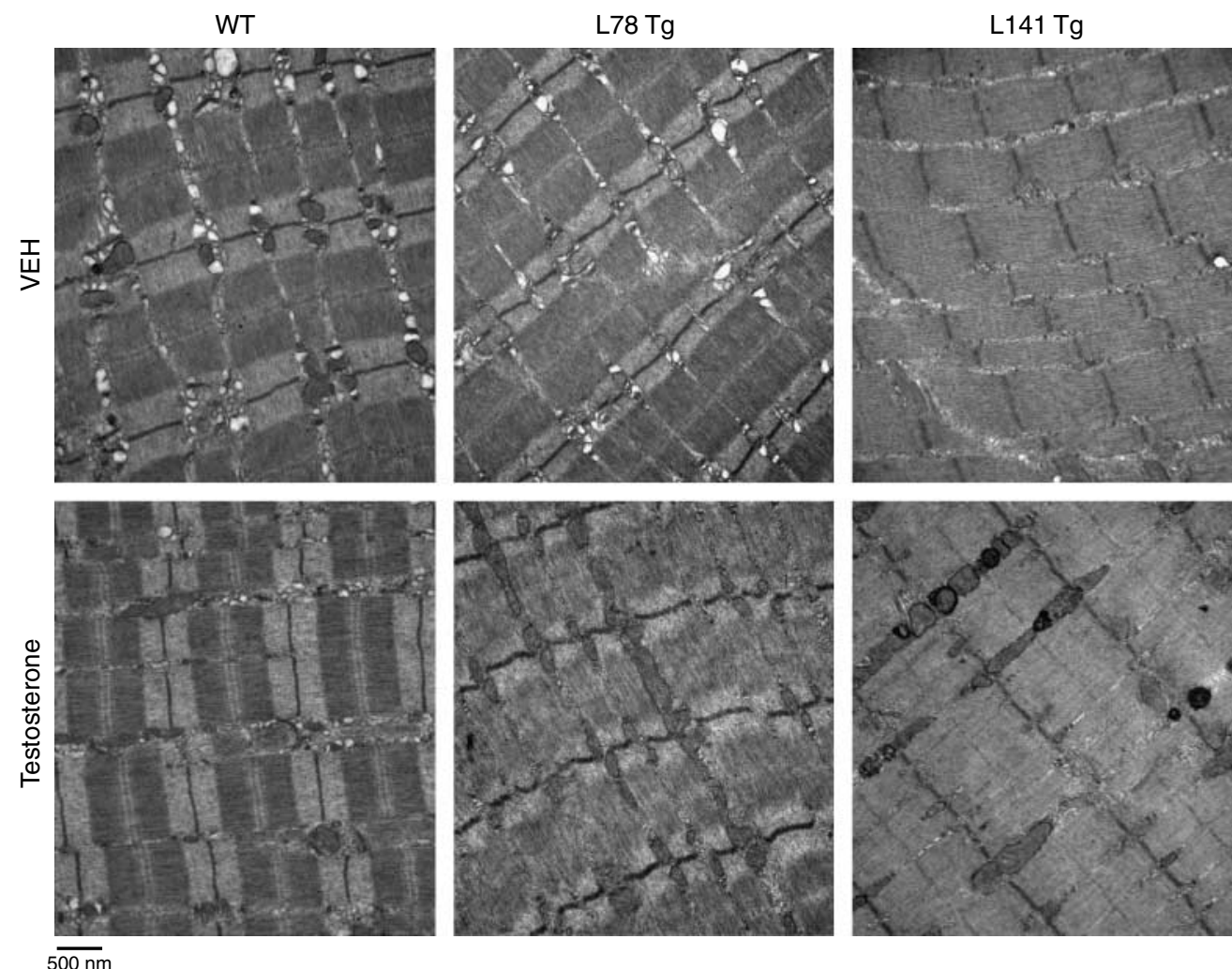

Figure 4 Testosterone treatment of female HSA-AR transgenic mice affects ultrastructure of skeletal muscle. Transmission electron micrographs EDL taken from wild-type (Wt - left), L78 transgenic ( $\mathrm{Tg}$ - middle), and L141 $\mathrm{Tg}$ (right). Figures in the top row depict myofibers from mice given a vehicle treatment for 7 days (VEH) and those in the bottom row depict myofibers of mice that received 7 days of testosterone treatment. Only testosteronetreated Tg animals show structural changes in fibrils and mitochondria, with L141 females showing the most severe alterations. Micrographs were taken on $20000 \times$ magnification, scale bar represents $500 \mathrm{~nm}$. 

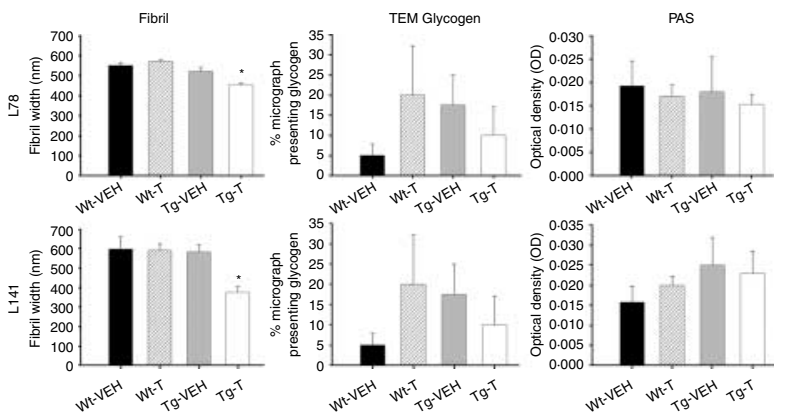

Figure 5 Testosterone treatment of female HSA-AR transgenic mice reduces fibril width but does not affect glycogen. (Left) Average myofibril width is reduced by testosterone treatment of both L78 transgenic ( $\mathrm{Tg}$ - top row) and L141 Tg (bottom row) but has no effect on Wt controls. (Middle) Glycogen content, measured as the percentage micrographs presenting with glycogen granules, was not significantly altered in any of the treatment groups from either L78 $\mathrm{Tg}$ (top row) or L141 Tg (bottom row). Measurements of fibril width and glycogen content were carried out on micrographs at $20000 \times$ and $40000 \times$ magnification respectively. Each group had eight subjects aged 97-202 days. (Right) PAS stain optical densities in L78 and L141 females. Regardless of genotype or treatment, optical densities of PAS stain were not significantly altered, indicating no effect on glycogen content. Optical densities measured at $40 \times$ magnification and were corrected to amylase-treated alternate sections. Sections were photographed at $400 \times$ magnification. Error bars represent S.E.M.; $* P<0 \cdot 05$ Tukey test indicating the significance of the difference in the activity of a given complex between $\mathrm{Tg}-\mathrm{T}$ and all other groups.

$\left(F_{1,29}=22 \cdot 642, \quad P=0 \cdot 005 ; \quad F_{1,29}=29 \cdot 772, \quad P=0 \cdot 001\right)$. Treatment also affected body weight in this line $\left(F_{1,29}=\right.$ 12.1, $P=0 \cdot 002)$. An interaction of genotype and treatment was observed for number of mitochondria $\left(F_{1,29}=33 \cdot 775\right.$, $P<0 \cdot 0001)$, mitochondrial area $\left(F_{1,29}=29 \cdot 929, P=0 \cdot 0002\right)$, and mitochondrial volume density $\left(F_{1,29}=25 \cdot 428\right.$, $P=0 \cdot 003)$. Tukey post hocs revealed that once again 7 days of testosterone treatment sufficed to increase mitochondrial volume density ( $\mathrm{Tg}-\mathrm{T}$ greater than all other groups $P<0 \cdot 01$; Fig. 6), profile area ( $\mathrm{Tg}-\mathrm{T}$ greater than all other groups $P<0 \cdot 01$; Fig. 6), and number (Tg-T greater than all other groups $P<0.05$; Fig. 6$)$ in $\mathrm{Tg}$ females relative to all other groups.

Mitochondrial activity was assessed through a biochemical assay of respiratory chain complexes I, II, III, and IV. Again, ANOVA was separately run for L78 and L141. In L78, an interaction between genotype and treatment in the activities of complexes I $\left(F_{1,29}=29 \cdot 570, P<0 \cdot 001\right)$, II $\left(F_{1,29}=24 \cdot 071\right.$, $P<0 \cdot 001)$, III $\left(F_{1,29}=23 \cdot 447, P<0 \cdot 001\right)$, and IV $\left(F_{1,29}=\right.$ 28.803, $P<0 \cdot 001)$ was observed. Similarly, in L141, an interaction between genotype and treatment in the activities of complexes I $\left(F_{1,29}=68 \cdot 158, P<0 \cdot 001\right)$, II $\left(F_{1,29}=21 \cdot 777\right.$, $P<0 \cdot 001)$, III $\left(F_{1,29}=36 \cdot 665, P<0 \cdot 001\right)$, and IV $\left(F_{1,29}=\right.$ $32 \cdot 051, P<0 \cdot 001)$ was observed. Tukey post hoc tests identified the $\mathrm{Tg}-\mathrm{T}$ group in both lines as the only group to significantly differ from all others such that activity was increased in this group (all comparisons $P<0 \cdot 05$, Table 2).
Changes in mitochondrial content were not associated with increased proportion of slow-twitch (type I) fibers

Alterations in mitochondria might be explained by a transition of muscle fibers from fast to slow twitch. However, no slow fibers were identified in AT muscle of Wt or Tg L78 males using antibody staining. Similarly, slow fibers were not found in female AT muscle regardless of treatment or genotype, whereas such fibers were identified in soleus muscle used as a negative control for the anti-fast myosin antibody. Representation of glycolytic (FG), oxidative (FO), and oxidative-glycolytic (FOG) fibers changed in a complex manner that does not obviously represent consistent fibertype switching as a result of increased myocytic AR signaling.

Whereas Wt L78 male AT muscle was mostly composed of oxidative fibers followed by glycolytic and oxidativeglycolytic fibers, each of the three types was equally represented in $\mathrm{Tg}$ L78 males. More specifically, the proportion of FO fibers was reduced $\left(t_{2,8}=3 \cdot 253, P<0 \cdot 05\right)$ and of FOG fibers increased $\left(t_{2,8}=-6 \cdot 441, P<0 \cdot 001\right)$ in $\mathrm{Tg}$ relative to $\mathrm{Wt}$ males (Fig. $7 \mathrm{~A}$ ). In $\mathrm{L} 141 \mathrm{Tg}$ females, fiber type differed according to an interaction among fiber type, genotype, and treatment $\left(F_{2,56}=6 \cdot 839, P=0 \cdot 023\right)$, such that the proportion of FO and FG fibers differed from one another only in Wt females treated with testosterone $\left(t_{2,3}=-4 \cdot 602\right.$, $P=0 \cdot 019$, Fig. 7B). In L78 females, fiber type differed according to an interaction between genotype and treatment $\left(F_{1,28}=5 \cdot 29, P=0 \cdot 04\right)$, such that Wt-VEH L78 females had a greater proportion of FOG fibers relative to mice in other groups $(P<0 \cdot 01$ for all groups; Fig. 7C). In addition, treatment of $\mathrm{Wt}$ females with testosterone resulted in an increase in the proportion of FO fibers relative to $\mathrm{VEH}-$ treated Wt females $\left(t_{2,6}=2 \cdot 58 ; P=0 \cdot 042\right)$.
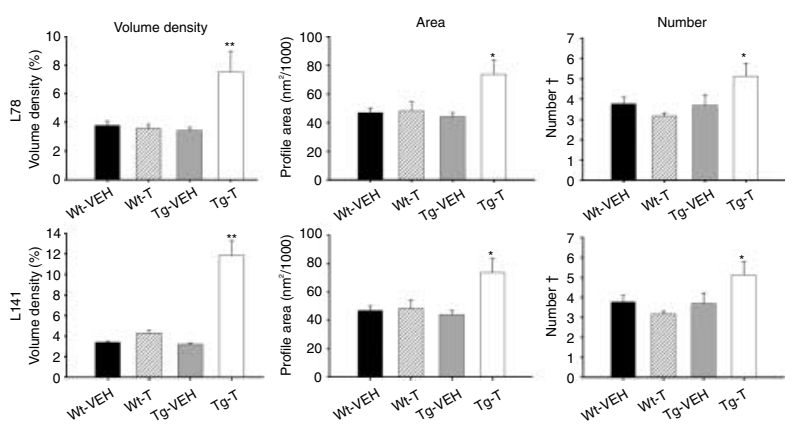

Figure 6 Testosterone treatment of female HSA-AR transgenic mice increases mitochondrial number and size in skeletal muscle. Mitochondrial volume density (left), average area (middle), and number (right) are all increased by testosterone treatment of both L78 transgenic ( $\mathrm{Tg}$ - top row) and L141 Tg (bottom row) but has no effect on Wt controls. Mitochondrial measurements were carried out on transmission electron micrographs taken at $40000 \times$ magnification. Each group had eight subjects aged 97-202 days. Error bars represent S.E.M.; ${ }^{*} P<0 \cdot 05 ;{ }^{*} P<0 \cdot 01$, Tukey test indicating the significance of the difference in the activity of a given complex between Tg-T and all other groups. 
Table 2 Respiratory complexes in skeletal muscle of testosterone-treated female mice. Transgenic (Tg) L78 and L141 females treated with testosterone, but not wild-type (Wt) or vehicle (VEH)-treated females, show increased specific activity of complexes I-IV of the respiratory chain measured in $\mathrm{nmol} / \mathrm{min}$ per $\mathrm{mg}$ protein. L141 females, which overexpress androgen receptor to a greater extent, show greater increases in enzymatic activity than L78 females

\begin{tabular}{|c|c|c|c|c|c|}
\hline Line & Complex & Wt-VEH & Wt-T & Tg-VEH & Tg-T \\
\hline \multirow{2}{*}{$\mathrm{L} 78$} & II & $358 \cdot 1 \pm 6 \cdot 7$ & $368 \cdot 3 \pm 7 \cdot 2$ & $354.9 \pm 3.5$ & $443 \cdot 3 \pm 12 \cdot 1^{*}$ \\
\hline & III & $991 \cdot 8 \pm 14 \cdot 4$ & $1010 \cdot 5 \pm 9 \cdot 7$ & $1002 \cdot 1 \pm 9 \cdot 3$ & $1141 \cdot 5 \pm 15 \cdot 3 *$ \\
\hline \multirow[t]{3}{*}{ L141 } & 1 & $271 \cdot 0 \pm 9 \cdot 5$ & $279 \cdot 3 \pm 6 \cdot 2$ & $272 \cdot 5 \pm 5 \cdot 1$ & $416 \cdot 3 \pm 11 \cdot 4^{*}$ \\
\hline & II & $369 \cdot 8 \pm 6 \cdot 3$ & $379 \cdot 3 \pm 8 \cdot 5$ & $368 \cdot 0 \pm 9 \cdot 3$ & $457 \cdot 5 \pm 8 \cdot 1^{*}$ \\
\hline & III & $996 \cdot 3 \pm 10 \cdot 8$ & $1014 \cdot 0 \pm 10 \cdot 5$ & $1018 \cdot 3 \pm 12 \cdot 8$ & $1228 \cdot 0 \pm 26 \cdot 9 *$ \\
\hline
\end{tabular}

${ }^{*} P<0.001$ Tukey test indicating the significance of the difference in the activity of a given complex between Tg-T and all other groups.

\section{Discussion}

The present results indicate that dramatic disruptions in myofibrillar ultrastructure are observed in myocytes of testosterone-exposed HSA-AR Tg mice, which overexpress AR. We observed significant alterations in myocyte mitochondria and sarcomeres in animals that exhibit neuromuscular atrophy (i.e. male $\mathrm{Tg}$ and testosterone-treated female $\mathrm{Tg}$ mice). These observations may provide an explanation for several known symptoms of HSA-AR mice. For example, motor deficits in these animals (Monks et al. 2007) may be related to decreased sarcomere size, and increased diaphorase staining in myocytes (Monks et al. 2007) would result from increased enzyme activity. Furthermore, alterations in body composition in HSA-AR mice (Fernando et al. 2010) might be explained by an increase in metabolic rate.

However, we cannot use the pathological features identified in this study to easily explain why L141 mice exhibit remarkably different pathology from L78 mice, because alterations in mitochondria and sarcomeres were consistently observed in both L78 and L141 animals. In the L141 line, pathology is usually lethal to developing males and testosterone-treated females, whereas the L78 line tolerates high levels of AR overexpression in myocytes. Similarly, L141 and L78 mice are divergent on many histopathological measures, and identifying the underlying cellular mechanisms or even the features of pathology that are uniquely associated with the most serious symptoms (e.g. motor impairment and wasting) has proven difficult (Monks et al. 2007). As we have argued elsewhere (Monks et al. 2008), this difficulty might be explained by a quantitative difference resulting in a threshold for pathology being met. We might, therefore, predict that testosterone-exposed L78 and L141 mice would exhibit similar alterations in cellular processes, but that they would be more pronounced in L141 mice, culminating in systemic dysfunction. Although we did not directly statistically compare the L78 and L141 lines in this study, the pattern of results with sarcomere width and mitochondrial morphology and activity appears consistent with this interpretation.
On the other hand, alterations in glycogen appear to be restricted to $\mathrm{Tg}$ males and therefore cannot account for the motor dysfunction observed in females.

It is tempting to speculate that the observed alterations in sarcomeres, mitochondria, and glycogen in myocytes of HSA-AR mice represent an exaggeration of normal AR function. However, the pathology of HSA-AR mice (Monks et al. 2007, Johansen et al. 2009) complicates this interpretation, raising the possibility that any changes seen are secondary to a pathological process. Although, we may be at least assured that these changes are independent of the most severe pathology (e.g. motor deficits and wasting), as similar alterations were generally observed in both L141 and L78 lines. It would be possible to test this idea by performing similar measurements in HSA-AR rats that also overexpress $\mathrm{AR}$ in myocytes, albeit to a lesser degree, and exhibit similar alterations in body composition and increases in respiration and metabolic rate (Fernando et al. 2010) but importantly do not have the motor deficits, wasting, or male lethality observed in HSA-AR mice. Regardless, the present results are largely consistent with proposed functions of myocyte $A R$ in regulating myofibrils, mitochondria, and myocyte glycogen.

\section{Anabolism of myofibrils}

Androgen-mediated increases in muscle mass in humans are associated with increased muscle fiber diameter (Marin et al. 1992, Hartgens et al. 2002, Ustunel et al. 2003). However, in laboratory mice and rats, we do not typically see alterations in myofiber size in limb muscles following androgen manipulations (Monks et al. 2004, Johansen et al. 2009, Chambon et al. 2010), although perineal muscles such as the levator ani do show marked reductions in myofiber size following androgen deprivation (Monks et al. 2004, Chambon et al. 2010), which is associated with myofibril disassembly (Venable 1966). For this reason, and given the dose and duration of testosterone treatment, we were not surprised that testosterone treatment had no significant effect on any measure in Wt females, consistent with our previous observations (Monks et al. 2007, 

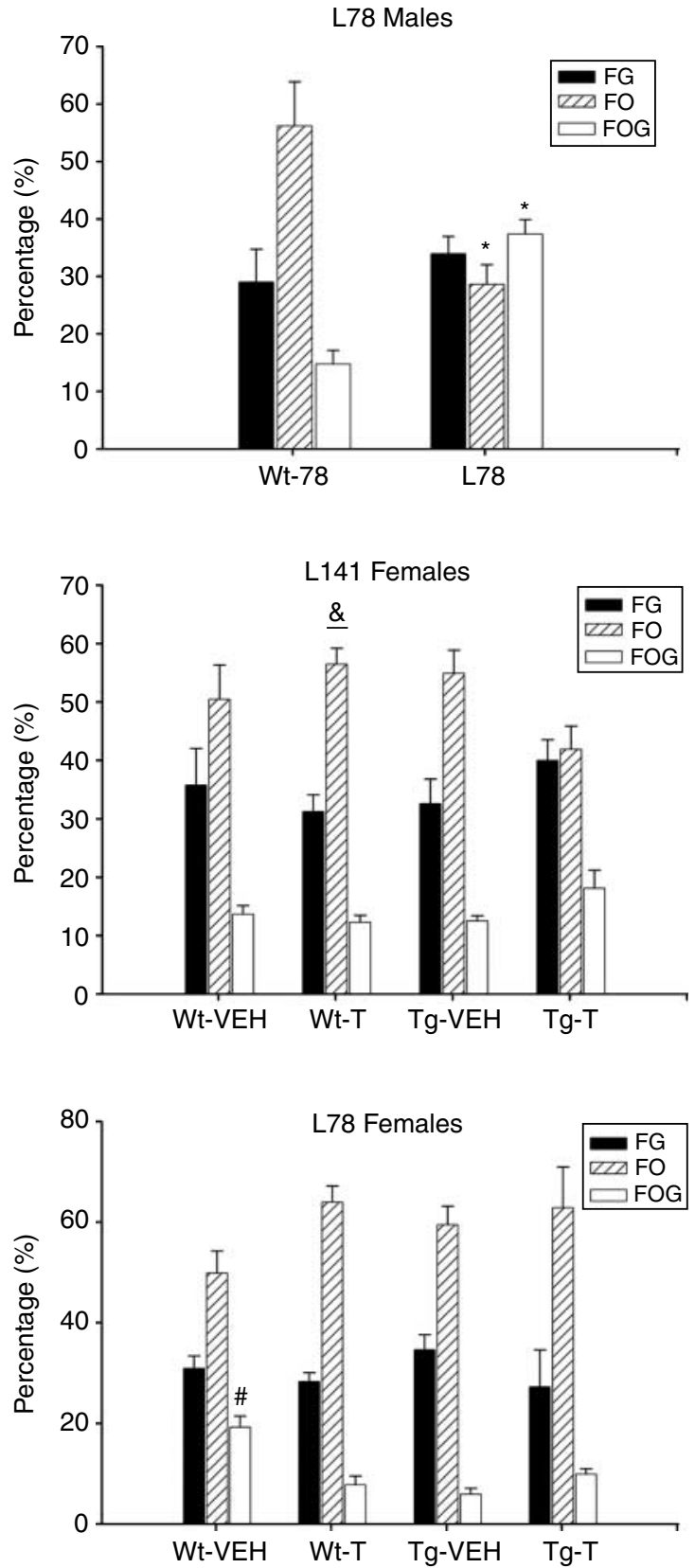

Figure 7 Increased mitochondrial content is not associated with fast to slow fiber-type switching. (A) Fiber-type representation in L78 males, (B) L141 females, and (C) L78 females. We found no slowtwitch fibers in AT muscles of either male or female mice irrespective of genotype or treatment. Fast-slow classification was carried out using a monoclonal anti-fast myosin antibody with soleus muscle sections as a negative control. Fibers were classified as glycolytic (FG), oxidative (FO), or oxidative-glycolytic (FOG) using an SDH stain wherein the darker the stain, the greater the oxidative capacity of the fiber. Error bars represent S.E.M.;

*significantly different $(P<0 \cdot 05)$ from Wt males. ${ }^{*}$ Significant difference in proportion of FG and FO fibers. "Significantly different $(P<0 \cdot 05)$ from all other experimental groups.
Johansen et al. 2009). Nonetheless, a straightforward function of myocyte AR in increasing myofibrillar width would predict that HSA-AR mice, which have increased AR signaling in myocytes, would also have greater myofibrillar width, whereas the opposite result was found. It seems likely then that this reduction in myofibrillar width in HSA-AR mice is related to pathology in these mice, which results in muscular atrophy, motor deficits, and weakness (Monks et al. 2007, Johansen et al. 2009). Interestingly, myofibrillar disruption is observed in muscle-specific ARKO mice (Chambon et al. 2010), which may indicate a paradoxical loss of normal AR function in HSA-AR mice. Indeed, microarray analysis of gene expression in skeletal muscle of HSA-AR mice indicated patterns of gene expression typical of those in ARKO mouse muscle (MacLean et al. 2008, Mo et al. 2010).

\section{Glycogen}

Using both electron microscopy and PAS staining, we find that increased androgen signaling results in increased glycogen content in skeletal muscle of male but not female HSA-AR mice. Androgenic stimulation of glycogen has previously been reported in male Wt rats (Bergamini 1975, Cunha et al. 2005) as well as a sexually dimorphic pattern of androgenic regulation of glycogen (Bergamini 1975). Therefore, it may be that the skeletal muscle glycogen response to androgen stimulation is developmentally organized by hormonal and/or genetic factors (Arnold 2009). The present results do not allow us to evaluate this possibility. Pathology in HSA-AR mice presents somewhat differently in male and testosteronetreated HSA-AR females (Monks et al. 2007), and it may be that the increased glycogen is related to pathology rather than an exaggeration of normal function of $\mathrm{AR}$ in myocytes. However, the fact that the severe muscular atrophy, motor deficits, and muscle weakness in testosterone-treated L141 females (Monks et al. 2007, Johansen et al. 2009) is not obviously accompanied by increases in glycogen (Fig. 5) argues against this last possibility.

\section{Mitochondria}

In contrast to glycogen, alterations in mitochondrial morphology and activity are reliably associated with pathology in HSA-AR mice. That is, we see alterations in mitochondria of both $\mathrm{Tg}$ males and testosterone-treated Tg females. This is consistent with a causative role for mitochondrial dysfunction, culminating in hypermetabolism, in the pathology of HSA-AR mice. Hypermetabolism is unlikely to represent the manifestation of fiber-type switching in favor of slow oxidative fibers as no such switch was evident on examination. Rather, the present results, taken together with studies of HSA-AR rats (Fernando et al. 2010), are consistent with a function of myocyte AR in simply increasing oxidative metabolism within myocytes via actions on mitochondria. In humans, insulin sensitivity and oxidative 
capacity are positively correlated with circulating testosterone (Pitteloud et al. 2005), and men have higher skeletal muscle expression of genes encoding mitochondrial proteins (Welle et al. 2008). Androgen supplementation in humans has been found to increase RMR either indirectly via increases in muscle mass (Welle et al. 1992, Mauras et al. 1998) or directly by increasing metabolic rate even when muscle mass is controlled for (Welle et al. 1992). In laboratory rats and mice, there is some evidence to suggest that systemic androgen treatment can affect mitochondria and/or oxidative metabolism. In mice, androgen-dependent sex differences exist in cytochrome oxidase $c$ activity (Koenig et al. 1980), and indices of oxidative capacity are positively correlated with circulating testosterone (Pitteloud et al. 2005). More direct evidence comes from studies of genetic manipulation of $A R$ in myocytes. We find that HSA-AR rats and mice have increased RMR and ETC activity (Fernando et al. 2010; Tables 1 and 2) and that HSA-AR mice have increased NADH/diaphorase staining (Monks et al. 2007, Johansen et al. 2009) and increased mitochondrial density, number, and/or size (Figs 1, 3,4 and 6). Increases in oxidative metabolism of HSA-AR mice and rats are not secondary to increases in muscle mass, indicating hypermetabolism.

Nonetheless, the literature regarding androgenic effects on oxidative metabolism is somewhat contradictory, and no simple relationship is likely to exist between variation in systemic androgens and metabolism. For example, suppressing testosterone secretion for 4 weeks in men does not obviously affect body composition or metabolic parameters (Rabiee et al. 2010). Furthermore, in laboratory rats and mice, testosterone supplementation can negatively affect mitochondrial parameters in skeletal muscle, including reduced citrate synthase activity (Pansarasa et al. 2002) and degeneration of mitochondria (Ustunel et al. (2003), but degeneration is also seen in castration (Oner et al. 2008)). Most puzzling, one strain of muscle-specific ARKO mice has an increased proportion of slow-twitch fibers and reduced fat body mass, suggestive of increased oxidative metabolism (Ophoff et al. 2009), although another myocyte-specific ARKO mouse does not show all of these changes (Chambon et al. 2010). It is possible that we might reconcile these disparate findings by an increased understanding of how androgens interact with diverse muscles and fiber types within muscle. For example, androgen treatment and exercise interact complexly to alter fiber type effects of testosterone treatment in gastrocnemius of rats (Pansarasa et al. 2002, Ustunel et al. 2003), and we find fiber-type specific alterations in muscle fibers of HSA-AR rats (Fernando et al. 2010).

The mechanism whereby myocyte AR affects mitochondria is presently unclear. It is possible that AR within myocytes affect mitochondrial structure and function by altering expression of genes that stimulate mitochondrial biogenesis (e.g. PGC1 $\alpha$; Lin et al. 2002). Similarly, myocyte AR may affect mitochondrial activity through interactions with critical transcriptional co-factors. Specifically, recent data has shown that steroid receptor co-factor 1 and transcriptional intermediary co-factor 2, two transcription co-factors that are important modulators of AR activity, play an important role in skeletal muscle mitochondrial activity by regulating the expression of uncoupling proteins (Duteil et al. 2010). Alternately or additionally, myocyte AR might directly associate with mitochondria to alter the function of their oxidative enzymes, or even the mitochondrial genome. There is precedent for both of these possibilities. For example, AR forms stable complexes with COXVb in cell lines (Beauchemin et al. 2001) and both estrogen receptor $\beta$ (Milanesi et al. 2009) and glucocorticoid receptor (GR; Weber et al. 2002) translocate into mitochondria in skeletal muscle with ligand. Furthermore, GR can affect expression of the mitochondrial genome (Scheller et al. 2000). Evaluation of these possible mechanisms awaits further experimentation.

\section{Summary and conclusions}

We have found ultrastructural and histological alterations in HSA-AR mice indicating myofibrillar degeneration, glycogen accumulation in males and mitochondrial hyperplasia, and hypertrophy. Furthermore, measurement of ETC enzyme activity and indirect calorimetry indicate that androgen-stimulated HSA-AR mice are hypermetabolic. These findings provide insight into the functions of myocyte AR and also into the subcellular basis of pathology in HSA-AR mice.

\section{Declaration of interest}

The authors declare that there is no conflict of interest that could be perceived as prejudicing the impartiality of the research reported.

\section{Funding}

The research reported in this manuscript received financial support from the National Institutes of Health ((http://www.nih.gov/) R01-NS51257 to D A M) and Natural Sciences and Research Council of Canada ((http://www. nserc-crsng.gc.ca/) 312458-06 to D A M).

\section{Acknowledgements}

We would like to thank Steve Doyle and Battista Calvieri for help with electron microscopy.

\section{References}

Arnold AP 2009 The organizational-activational hypothesis as the foundation for a unified theory of sexual differentiation of all mammalian tissues. Hormones and Behavior 55 570-578. (doi:10.1016/j.yhbeh.2009.03.011) Basaria S, Lieb J II, Tang AM, DeWeese T, Carducci M, Eisenberger M \& Dobs AS 2002 Long-term effects of androgen deprivation therapy in prostate cancer patients. Clinical Endocrinology 56 779-786. (doi:10.1046/ j.1365-2265.2002.01551.x) 
Basaria S, Coviello AD, Travison TG, Storer TW, Farwell WR, Jette AM, Eder R, Tennstedt S, Ulloor J, Zhang A et al. 2010 Adverse events associated with testosterone administration. New England Journal of Medicine 363 109-122. (doi:10.1056/NEJMoa1000485)

Beauchemin AM, Gottlieb B, Beitel LK, Elhaji YA, Pinsky L \& Trifiro MA 2001 Cytochrome $c$ oxidase subunit $\mathrm{Vb}$ interacts with human androgen receptor: a potential mechanism for neurotoxicity in spinobulbar muscular atrophy. Brain Research Bulletin 56 285-297. (doi:10.1016/S0361-9230(01) 00583-4)

Bergamini E 1975 Different mechanisms in testosterone action on glycogen metabolism in rat perineal and skeletal muscles. Endocrinology 96 77-84. (doi:10.1210/endo-96-1-77)

Bhasin S, Storer TW, Berman N, Callegari C, Clevenger B, Phillips J, Bunnell TJ, Tricker R, Shirazi A \& Casaburi R 1996 The effects of supraphysiologic doses of testosterone on muscle size and strength in normal men. New England Journal of Medicine 335 1-7. (doi:10.1056/NEJM19960704335 0101)

Bhasin S, Woodhouse L, Casaburi R, Singh AB, Mac RP, Lee M, Yarasheski KE, Sinha-Hikim I, Dzekov C, Dzekov J et al. 2005 Older men are as responsive as young men to the anabolic effects of graded doses of testosterone on the skeletal muscle. Journal of Clinical Endocrinology and Metabolism 90 678-688. (doi:10.1210/jc.2004-1184)

Chambon C, Duteil D, Vignaud A, Ferry A, Messaddeq N, Malivindi R, Kato S, Chambon P \& Metzger D 2010 Myocytic androgen receptor controls the strength but not the mass of limb muscles. PNAS 107 14327-14332. (doi:10.1073/pnas.1009536107)

Cunha TS, Tanno AP, Costa Sampaio Moura MJ \& Marcondes FK 2005 Influence of high-intensity exercise training and anabolic androgenic steroid treatment on rat tissue glycogen content. Life Sciences 77 1030-1043. (doi:10.1016/j.lfs.2005.03.001)

Duteil D, Chambon C, Ali F, Malivindi R, Zoll J, Kato S, Geny B, Chambon P \& Metzger D 2010 The transcriptional coregulators TIF2 and SRC-1 regulate energy homeostasis by modulating mitochondrial respiration in skeletal muscles. Cell Metabolism 12 496-508. (doi:10.1016/j.cmet.2010.09. 016)

Fairchild TJ \& Fournier PA 2004 Glycogen determination using periodic acid-Schiff: artifact of muscle preparation. Medicine and Science in Sports and Exercise 36 2053-2058.

Ferrando AA, Sheffield-Moore M, Yeckel CW, Gilkison C, Jiang J, Achacosa A, Lieberman SA, Tipton K, Wolfe RR \& Urban RJ 2002 Testosterone administration to older men improves muscle function: molecular and physiological mechanisms. American Journal of Physiology. Endocrinology and Metabolism 282 E601-E607. (doi:10.1152/ajpendo.00362.2001)

Ferrando AA, Sheffield-Moore M, Paddon-Jones D, Wolfe RR \& Urban RJ 2003 Differential anabolic effects of testosterone and amino acid feeding in older men. Journal of Clinical Endocrinology and Metabolism 88 358-362. (doi:10.1210/jc.2002-021041)

Fernando SM, Rao P, Niel L, Chatterjee D, Stagljar M \& Monks DA 2010 Myocyte androgen receptors increase metabolic rate and improve body composition by reducing fat mass. Endocrinology 151 3125-3132. (doi:10. 1210/en.2010-0018)

Forbes GB, Porta CR, Herr BE \& Griggs RC 1992 Sequence of changes in body composition induced by testosterone and reversal of changes after drug is stopped. Journal of the American Medical Association 267 397-399. (doi:10.1001/jama.267.3.397)

Hartgens F, van Straaten H, Fideldij S, Rietjens G, Keizer HA \& Kuipers H 2002 Misuse of androgenic-anabolic steroids and human deltoid muscle fibers: differences between polydrug regimens and single drug administration. European Journal of Applied Physiology 86 233-239. (doi:10.1007/ s00421-001-0535-7)

Herbst KL \& Bhasin S 2004 Testosterone action on skeletal muscle. Current Opinion in Clinical Nutrition and Metabolic Care 7 271-277. (doi:10.1097/ 00075197-200405000-00006)

Huguenard AL, Fernando SM, Monks DA \& Sengelaub DR 2011 Overexpression of androgen receptors in target musculature confers androgen sensitivity to motoneuron dendrites. Endocrinology 152 639-650. (doi:10.1210/en.2010-1197)
Johansen JA, Yu Z, Mo K, Monks DA, Lieberman AP, Breedlove SM \& Jordan CL 2009 Recovery of function in a myogenic mouse model of spinal bulbar muscular atrophy. Neurobiology of Disease 34 113-120. (doi:10.1016/j.nbd. 2008.12.009)

Kirby DM, Thorburn DR, Turnbull DM \& Taylor RW 2007 Biochemical assays of respiratory chain complex activity. Methods in Cell Biology $\mathbf{8 0}$ 93-119. (doi:10.1016/S0091-679X(06)80004-X)

Koenig H, Goldstone A \& Lu CY 1980 Androgens regulate mitochondrial cytochrome $c$ oxidase and lysosomal hydrolases in mouse skeletal muscle. Biochemical Journal 192 349-353.

van der Laarse WJ, van Noort P \& Diegenbach PC 1992 Calibration of quantitative histochemical methods: estimation of glycogen content of muscle fibers using the PAS reaction. Biotechnic and Histochemistry 67 303-308. (doi:10.3109/10520299209110039)

Lin J, Wu H, Tarr PT, Zhang CY, Wu Z, Boss O, Michael LF, Puigserver P, Isotani E, Olson EN et al. 2002 Transcriptional co-activator PGC-1 alpha drives the formation of slow-twitch muscle fibres. Nature 418 797-801. (doi:10.1038/nature00904)

MacLean HE, Chiu WS, Notini AJ, Axell AM, Davey RA, McManus JF, Ma C, Plant DR, Lynch GS \& Zajac JD 2008 Impaired skeletal muscle development and function in male, but not female, genomic androgen receptor knockout mice. FASEB Journal 22 2676-2689. (doi:10.1096/ fj. 08-105726)

MacLean HE \& Handelsman DJ 2009 Unraveling androgen action in muscle: genetic tools probing cellular mechanisms. Endocrinology 150 3437-3439. (doi:10.1210/en.2009-0438)

Marin P, Krotkiewski M \& Bjorntorp P 1992 Androgen treatment of middleaged, obese men: effects on metabolism, muscle and adipose tissues. European Journal of Medicine 1 329-336.

Mauras N, Hayes V, Welch S, Rini A, Helgeson K, Dokler M, Veldhuis JD \& Urban RJ 1998 Testosterone deficiency in young men: marked alterations in whole body protein kinetics, strength, and adiposity. Journal of Clinical Endocrinology and Metabolism 83 1886-1892. (doi:10.1210/jc.83.6.1886)

Milanesi L, Vasconsuelo A, de Boland AR \& Boland R 2009 Expression and subcellular distribution of native estrogen receptor beta in murine $\mathrm{C} 2 \mathrm{C} 12$ cells and skeletal muscle tissue. Steroids 74 489-497. (doi:10.1016/j.steroids. 2009.01.005)

Mo K, Razak Z, Rao PR, Yu Z, Adachi H, Katsuno M, Sobue G, Lieberman AP, Westwood JT \& Monks DA 2010 Microarray analysis of gene expression by skeletal muscle of three mouse models of Kennedy disease/spinal bulbar muscular atrophy. PLoS ONE 5 1-8. (doi:10.1371/ journal.pone.0012922)

Monks DA, O'Bryant EL \& Jordan CL 2004 Androgen receptor immunoreactivity in skeletal muscle: enrichment at the neuromuscular junction. Journal of Comparative Neurology 473 59-72. (doi:10.1002/cne.20088)

Monks DA, Johansen JA, Mo K, Rao P, Eagleson B, Yu Z, Lieberman AP, Breedlove SM \& Jordan CL 2007 Overexpression of wild-type androgen receptor in muscle recapitulates polyglutamine disease. PNAS 104 18259-18264. (doi:10.1073/pnas.0705501104)

Monks DA, Rao P, Mo K, Johansen J, Lewis G \& Kemp M 2008 Androgen receptor and Kennedy disease/spinal bulbar muscular atrophy. Hormones and Behavior 53 729-740. (doi:10.1016/j.yhbeh.2007.12.009)

Niel L, Shah AH, Lewis GA, Mo K, Chatterjee D, Fernando SM, Hong MH, Chang WY, Vollmayr P, Rosen J et al. 2009 Sexual differentiation of the spinal nucleus of the bulbocavernosus is not mediated solely by androgen receptors in muscle fibers. Endocrinology 150 3207-3213. (doi:10.1210/en. 2008-1478)

Oner J, Oner H, Sahin Z, Demir R \& Ustunel I 2008 Melatonin is as effective as testosterone in the prevention of soleus muscle atrophy induced by castration in rats. Anatomical Record 291 448-455. (doi:10.1002/ar.20659)

Ophoff J, Van Proeyen K, Callewaert F, De Gendt K, De Bock K, Van den Bosch A, Verhoeven G, Hespel P \& Vanderschueren D 2009 Androgen signaling in myocytes contributes to the maintenance of muscle mass and fiber type regulation but not to muscle strength or fatigue. Endocrinology $\mathbf{1 5 0}$ 3558-3566. (doi:10.1210/en.2008-1509)

Orr R \& Fiatarone Singh M 2004 The anabolic androgenic steroid oxandrolone in the treatment of wasting and catabolic disorders: review of efficacy and safety. Drugs 64 725-750. (doi:10.2165/00003495-200464070-00004) 
Pansarasa O, D’Antona G, Gualea MR, Marzani B, Pellegrino MA \& Marzatico F 2002 "Oxidative stress": effects of mild endurance training and testosterone treatment on rat gastrocnemius muscle. European Journal of Applied Physiology 87 550-555. (doi:10.1007/s00421-002-0668-3)

Pitteloud N, Mootha VK, Dwyer AA, Hardin M, Lee H, Eriksson KF, Tripathy D, Yialamas M, Groop L, Elahi D et al. 2005 Relationship between testosterone levels, insulin sensitivity, and mitochondrial function in men. Diabetes Care 28 1636-1642. (doi:10.2337/diacare.28.7.1636)

Rabiee A, Dwyer AA, Caronia LM, Hayes FJ, Yialamas MA, Andersen DK, Thomas B, Torriani M \& Elahi D 2010 Impact of acute biochemical castration on insulin sensitivity in healthy adult men. Endocrine Research $\mathbf{3 5}$ 71-84. (doi:10.3109/07435801003705601)

Scheller K, Sekeris CE, Krohne G, Hock R, Hansen IA \& Scheer U 2000 Localization of glucocorticoid hormone receptors in mitochondria of human cells. European Journal of Cell Biology 79 299-307. (doi:10.1078/ S0171-9335(04)70033-3)

Schroeder ET, Singh A, Bhasin S, Storer TW, Azen C, Davidson T, Martinez C, Sinha-Hikim I, Jaque SV, Terk M et al. 2003 Effects of an oral androgen on muscle and metabolism in older, community-dwelling men. American Journal of Physiology. Endocrinology and Metabolism 284 E120-E128. (doi:10. 1152/ajpendo.00363.2002)

Storer TW, Magliano L, Woodhouse L, Lee ML, Dzekov C, Dzekov J, Casaburi R \& Bhasin S 2003 Testosterone dose-dependently increases maximal voluntary strength and leg power, but does not affect fatigability or specific tension. Journal of Clinical Endocrinology and Metabolism $\mathbf{8 8}$ 1478-1485. (doi:10.1210/jc.2002-021231)

Storer TW, Woodhouse L, Magliano L, Singh AB, Dzekov C, Dzekov J \& Bhasin S 2008 Changes in muscle mass, muscle strength, and power but not physical function are related to testosterone dose in healthy older men. Journal of the American Geriatrics Society 56 1991-1999. (doi:10.1111/j.15325415.2008.01927.x)

Ustunel I, Akkoyunlu G \& Demir R 2003 The effect of testosterone on gastrocnemius muscle fibres in growing and adult male and female rats: a histochemical, morphometric and ultrastructural study. Anatomia, Histologia, Embryologia 32 70-79. (doi:10.1046/j.1439-0264.2003.00441.x)
Venable JH 1966 Morphology of the cells of normal, testosterone-deprived and testosterone-stimulated levator ani muscles. American Journal of Anatomy 119 271-301. (doi:10.1002/aja.1001190206)

Wang C, Cunningham G, Dobs A, Iranmanesh A, Matsumoto AM, Snyder PJ, Weber T, Berman N, Hull L \& Swerdloff RS 2004 Long-term testosterone gel (AndroGel) treatment maintains beneficial effects on sexual function and mood, lean and fat mass, and bone mineral density in hypogonadal men. Journal of Clinical Endocrinology and Metabolism 89 2085-2098. (doi:10.1210/jc.2003-032006)

Weber K, Bruck P, Mikes Z, Küpper JH, Klingenspor M \& Wiesner RJ 2002 Glucocorticoid hormone stimulates mitochondrial biogenesis specifically in skeletal muscle. Endocrinology 143 177-184. (doi:10.1210/en.143.1.177)

Weibel ER 1979 Stereological methods, volume 1, practical methods for Biological morphometry. London: Academic Press.

Welle S, Jozefowicz R, Forbes G \& Griggs RC 1992 Effect of testosterone on metabolic rate and body composition in normal men and men with muscular dystrophy. Journal of Clinical Endocrinology and Metabolism $\mathbf{7 4}$ 332-335. (doi:10.1210/jc.74.2.332)

Welle S, Tawil R \& Thornton CA 2008 Sex-related differences in gene expression in human skeletal muscle. PLoS ONE 3 e1385. (doi:10.1371/ journal.pone.0001385)

Woodhouse LJ, Reisz-Porszasz S, Javanbakht M, Storer TW, Lee M, Zerounian H \& Bhasin S 2003 Development of models to predict anabolic response to testosterone administration in healthy young men. American Journal of Physiology. Endocrinology and Metabolism 284 E1009-E1017. (doi:10.1152/ajpendo.00536.2002)

\section{Received in final form 15 April 2011 \\ Accepted 9 May 2011 Made available online as an Accepted Preprint 9 May 2011}

